\title{
LEISHMANIOSE TEGUMENTAR NO OESTE DO ESTADO DE SANTA CATARINA, BRASIL.
}

\author{
Paulo de Tarso São Thiago e Ubiracy Guida
}

\begin{abstract}
Os autores procederam à investigaçāo clínico-epidemiológica em 22 pacientes suspeitos de leishmaniose tegumentar nos municipios de Quilombo e Coronel Freitas, Oeste de Santa Catarina. Em 5 desses pacientes, foi realizada apenas a reação intradérmica de Montenegro; em 5 , somenteo raspado ou punção das lesōes e, em 8 , ambos os exames. Não foi feito nenhum exame laboratorial em 4 casos. Consideraram confirmado o caso suspeito que se enquadrasse em um ou mais dos seguintes itens: 1 . raspado ou punção positiva; 2 . reaçâo intradérmica positiva + lesóes clinicamente compativeis; 3. lesóes clinicamente compativeis + resposta favorável ao tratamento especifico, com cicatriza fão das lesōes. Quatorze, dos 22 pacientes suspeitos, foram considerados casos confirmados, 11 dos quais autóctones da área, estabelecendo-se assim a existência de um foco da doença no Estado. Entre os casos autóctones, 5 tiveram o raspado/ punçāo positivo. Todos os casos tinham idade acima de 15 anos e havia um nitido predominio do sexo masculino.
\end{abstract}

\section{Palavras-chaves: Leishmaniose tegumentar, Sarta Catarina. Brasil.}

A única informação anterior sobre a existência de leishmaniose tegumentar em Santa Catarina é a de Pessôa e Martins ${ }^{9}$, segundo a qual Terra e Crissiuma teriam confirmado em 1913, pelo encontro do parasita, a doença em todos os Estados do Brasil.

Nos últimos anos, entretanto, os postos de saúde do Oeste catarinense passaram a solicitar à Diretoria Regional da Superintendência de Campanhas de Saúde Pública (SUCAM) medicação especifica para leishmaniose.

Em julho de 1987, estivemos na região e pudemos observar, nos municípios de Quilombo e Coronel Freitas, algumas pessoas com lesōes tipicas da parasitose. Desde então, temos realizado investigação clínico-epidemiológica e exames laboratoriais de casos suspeitos. Muitos desses casos eram autóctones da área e foram considerados como positivos para leishmaniose tegumentar, confirmando-se assim a existência de um foco de transmissão no Estado.

\section{Descrição da Área}

Os municípios de Quilombo e Coronel Freitas, contiguos entre si, cujas áreas urbanas distam $674 \mathrm{~km}$ e $643 \mathrm{~km}$ de Florianópolis, respectivamente, situamse numa área do Oeste catarinense onde o relevo é ondulado e os solos são férteis, originários de rochas básicas. O clima é superúmido, mesotérmico brando, sujeito a geadas no inverno, com máximo de precipitação na primavera e mínimo no verão 8 .

Esses municipios são ocupados por pequenos proprietários, a maioria descendentes de colonos

Superintendência de Campanhas de Saúde Pública (SUCAM).

Endereço para correspondência: Dr. Paulo de Tarso São Thiago. CP: 196,88095 Florianópolis, SC, Brasil.

Recebido para publicação em 04/06/90. italianos, e neles predominam lavouras de milho, feijão e mandioca. O forte da economia regional é, entretanto, a criação intensiva de aves e suínos, patrocinada pelos grandes frigorificos do Estado. A criação de gado leiteiro é encontrada em menor escala. A atividade madeireira, baseada nos restos de mata, ainda existentes, está chegando ao fim.

As casas são, em sua maioria, de madeira, mas muito bem acabadas e com todo o conforto possivel em zona rural.

\section{MATERIAL E MÉTODOS}

$\mathrm{Na}$ investigação clinico-epidemiológica foram coletados dados relativos a: idade, sexo, residencia, naturalidade, ocupação, movimentação, características e época de início das lesões. Registraram-se também exames complementares, tratamentos realizados e evolução clínica após tratamento.

Vinte e dois casos suspeitos e residentes na área foram submetidos a essa investigação e acompanhados através contatos periódicos.

A reação intradérmica de Montenegro ${ }^{7}$ foi realizada em 5 desses casos suspeitos, o raspado ou punção das lesões em outros 5 e em 8 casos foram realizados ambos os exames.

Em 4 casos, não foi feito nenhum exame laboratorial.

A reação intradérmica de Montenegro, realizada em 13 dos 22 pacientes, consistiu na inoculação de $0,1 \mathrm{ml}$ do antigeno na face ventral do antebraço esquerdo. Na mesma regiào do outro antebraço, inoculou-se $0,1 \mathrm{ml}$ de solução salina, para servir de controle. A leitura foi feita 48 horas depois da inoculação. A reação foi considerada positiva quando, no local da inoculação, surgiu um halo de enduração de $5 \mathrm{~mm}$ ou mais de diâmetro, com ou sem a ocorrência de halo de eritema. A técnica e o critério de positividade descritos basearam-se nos trabalhos de diversos autores 123610 . O antigeno, fornecido pelo Sr. Luiz Alberto Alves Molina, da Diretoria Regional de 
Goiás da SUCAM, e preparada pelo Prof. William Barbosa, da Universidade Federal de Goiás, era constituído de material elaborado a partir de formas promastigotas de Leishmania brasiliensis, cultivadas em meio de $\mathrm{RQ}^{*}$ e diluído em solução fluoretada fenolada. A cepa é identificada como Alceu Acácia, proveniente de São Paulo, e mt-L1, Goiás, Goiânia. Concentração do antigeno- 5: escala de Mac Farland.

Dos 13 pacientes submetidos ao raspado ou punção das lesões, em 9 este exame foi feito por nós. Para tal, procedemos à preparação de esfregaço do material em lâmina, fixado em álcool metílico e corado com Giemsa, durante 30 minutos, conforme técnica utilizada por Bonfante-Garrido e Barreto ${ }^{2}$.

Quatro pacientes haviam sido submetidos a este exame por parte de terceiros.

Dezesseis, dos 22 casos suspeitos, foram tratados com antimoniato de Meglumina (glucantime), ampolas de $5 \mathrm{ml}$, com quantidades totais que variavam de 25 a 75 ampolas. Alguns tratamentos ficaram sob nossa responsabilidade e outros sob a responsabilidade de médicos ou farmacêuticos locais.

Com referência a critérios de positividade, consideramos como caso de leishmaniose tegumentar confirmado aquele que tenha se enquadrado em um ou mais dos seguintes itens: 1 . raspado ou punção positiva; 2. reação intradérmica positiva + lesões clinicamente compatíveis; 3 . lesões clinicamente compa- tiveis + resposta favorável ao tratamento específico, com cicatrização da lesão.

\section{RESULTADOS E DISCUSSÃO}

Dos 22 pacientes suspeitos, 14 foram considerados positivos para leishmaniose, 11 dos quais autóctones da área.

A confirmação diagnóstica destes 11 casos baseou-se nos seguintes resultados:

- Três casos pela positividade da reação intradérmica e por critérios clínico-terapêuticos. Em dois desses casos, a punção/raspado não foi realizada e, em um, este exame resultou negativo.

- Três casos pelo encontro de parasitos nas lesões e por critérios clinico-terapêuticos. Em dois desses casos, a reação intradérmica não foi realizada e, em um, esta reação resultou negativa.

- Dois casos pelo encontro de parasitos, pela positividade da reação intradérmica e por critérios clínico-terapêuticos.

- Três casos confirmados apenas pela presença de lesōes compativeis e pela resposta favorável à terapêutica especifica. Em um desses casos, a reação intradérmica e a punção/raspado foram negativas; em outro caso, a intradérmica não foi realizada e a punção/raspado resultou negativa; no terceiro caso, estes exames não foram realizados. (Tabela 1).

Tabela 1 -Dados referentes à identificafãa, investigação epidemiológica, exame clínico-laboratorial e evolução de casos confirmados de leishmaniose tegumentar - Santa Catarina, Brasil, 1987-1988.

\begin{tabular}{|c|c|c|c|c|c|c|c|c|}
\hline $\begin{array}{l}\text { Caso } \\
\text { no }\end{array}$ & Idade/Sexo & $\begin{array}{l}\text { Município de } \\
\text { residência }\end{array}$ & Origem & $\begin{array}{l}\text { Tempo de } \\
\text { evolução } \\
\text { em meses }\end{array}$ & $\begin{array}{l}\text { Resultado } \\
\text { do exame } \\
\text { clínico }\end{array}$ & $\begin{array}{c}\text { I.R. de } \\
\text { Montenegro }\end{array}$ & $\begin{array}{l}\text { Raspado ou } \\
\text { punção } \\
\text { das lesões }\end{array}$ & $\begin{array}{c}\text { Resposta } \\
\text { ao } \\
\text { tratamento }\end{array}$ \\
\hline 01 & $61 \mathrm{M}$ & Quilombo & Importado & 2 & Compatível & Pos. $(12 \mathrm{~mm})$ & Negativo & Favorável \\
\hline 02 & $60 \mathrm{M}$ & Quilombo & Autóctone & 7 & Compativel & Nào realizado & Pós-P/outros & Favorável \\
\hline 04 & $44 \mathrm{M}$ & Quilombo & Autóctone & 1,5 & Compativel & Não realizado & Não realizado & Favorável \\
\hline 05 & $29 \mathrm{M}$ & Quilombo & Autóctone & 8 & Compativel & Não realizado & Neg-P/outros & Favorável \\
\hline 06 & $48 \mathrm{M}$ & Quilombo & Autóctone & 0,5 & Compativel & Pos. (15 mm) & Não realizado & Favorável \\
\hline 09 & $23 \mathrm{~F}$ & Quilombo & Autóctone & 10 & Compativel & Não realizado & Pos-P/outros & Favorável \\
\hline 10 & $18 \mathrm{~F}$ & Coronel Freitas & Autóctone & 5 & Compativel & Pos. $(10 \mathrm{~mm})$ & Pos-P/outros & Favorável \\
\hline 13 & $43 \mathrm{~F}$ & Coronel Freitas & Autóctone & 12 & Compativel & Pos. (20 mm) & Não realizado & Favorável \\
\hline 15 & $31 \mathrm{M}$ & Quilombo & Importado & $?$ & Compativel & Não realizado & Negativo & Favorável \\
\hline 16 & $42 \mathrm{~F}$ & Quilombo & Importado & $\dot{3}$ & Compativel & Não realizado & Não realizado & Favorável \\
\hline 17 & $15 \mathrm{M}$ & Quilombo & Autóctone & 3 & Compativel & Negativo & Negativo & Favorável \\
\hline 18 & $21 \mathrm{M}$ & Quilombo & Autóctone & 3 & $\mathrm{Co} 2 \mathrm{el}$ & Pos. $(13 \mathrm{~mm})$ & Positivo & Favorável \\
\hline 19 & $68 \mathrm{M}$ & Quilombo & Autóctone & 6 & Compativel & Negativo & Positivo & Favorável \\
\hline 24 & $25 \mathrm{M}$ & Quilombo & Autóctone & 7 & Compativel & Pos. $(17 \mathrm{~mm})$ & Negativo & Favorável \\
\hline
\end{tabular}

Obs. Pos-P/outros = Positivo. Exame realizado por terceiros.

* = Do início da doença até o início do tratamento.

Verifica-se assim que, dos oito casos autóctones submetidos à punção/raspado, cinco foram positivos.

O diâmetro da pápula de enduração na reação intradérmica variou de 10 a $17 \mathrm{~mm}$, com média aritmética de $15 \mathrm{~mm}$, considerando exclusivamente os casos confirmados e autóctones.

Todos os casos submetidos ao teste de Montenegro ou apresentaram pápula de enduração com

* Novo meio de cultura elaborado pelo Prof. William Barbosa. diâmetro igual ou superior a $10 \mathrm{~mm}$ ou não apresentaram pápula alguma.

Dos 11 casos autóctones, oito eram do sexo masculino, sendo que as idades variavam de 15 a 68 anos, com média aritmética de 35,8 anos. Esta distribuição sugere transmissão preferencial no extradomicílio.

Semelhante composição por idade e sexo foi encontrada em trabalhos de outros autores ${ }^{12}$, os quais igualmente apresentaram a hipótese de predomínio da transmissão extradomiciliar. 
Uma característica comum a todas as propriedades, onde ocorreram casos de leishmaniose, é terem abrigos de suínos ou de bovinos próximos à moradia.

A espécie de flebótomo predominante, nesses abrigos de animais, é a Lutzomyia intermedia (JA Ferreira Neto: comunicação pessoal, 1987). É uma situaçāo semelhante à encontrada no Rio de Janeiro e no litoral de São Paulo4.

As lesões consideradas compativeis constituíram-se em feridas ulceradas, com diâmetros que variavam de 1 a $5 \mathrm{~cm}$, circulares ou elípticas, limites nítidos e bordos elevados, fundos crostosos ou seropurulentos. Essas características se assemelham às lesões abertas descritas por outros autores 25 .

Quando cicatrizadas, apresentavam aspecto de mácula de bordos escuros e parte central clara.

Conforme informaçāo dos pacientes, em geral as lesões iniciavam por uma "pequena espinha" ou por algo "como uma picada de mosquito", pruriginosa e que evoluía lentamente para uma ferida ulcerada. casuística.

Lesões mucosas estiveram ausentes da nossa

\section{SUMMARY}

A survey was performed among 22 patients with ulcers suspected of leishmanial origin in the municipalities of Quilombo and Coronel Freitas, west of Santa Catarina State. From 5 patients only smears from the ulcers were examined, 5 others were submitted to Montenegro's intradermal test and in 8 both methods were used. Cases were regarded as confirmed when: 1 . parasites were found in the ulcer smears; 2 . the lesions were clinically characteristic and the skin test was positive and 3. the clinically characteristic lesions healed after specific treatment. Fourteen patients were regarded as confirmed cases, 11 being autochthonous, showing that transmission of cutaneous leishmaniasis accurs in the State. Of the autochthonous cases 5 showed parasites in the skin smears. Most patients were males and all were older than 15 years of age.

Key-words: Cutaneous leishmaniasis. Santa Catarina. Brazil.

\section{AGRADECIMENTOS}

Somos gratos aos colegas Joaquim Alves Ferreira Neto e Mário B. Aragão, pelas orientações e críticas construtivas.
Agradecemos também a Dra. Helena Keiko Toma, bolsista do Departamento de Microbiologia e Parasitologia da Universidade Federal de Santa Catarina, pela efetiva colaboração a nivel de campo e de laboratório, e ao Prof. Mário Steindel, daquele Departamento, pela orientação e ajuda a nível de laboratório.

\section{REFERÊNCIAS BIBLIOGRÁFICAS}

1. Barreto AC, Cuba CAC, Marsden PD, Vexanat JA, Belder MD. Características epidemiológicas da leishmaniose tegumentar americana em uma regiāo endêmica do Estado da Bahia, Brasil. I. Leishmaniose humana. Boletin de la Oficina Sanitária Panamericana 90: 415424, 1981.

2. Bonfante-Garrido R, Barreto T. Leishmaniasis tegumentaria americana en el Distrito Urdaneta, Venezuela. Boletin de la Oficina Sanitária Panamericana 91: 30-38, 1981.

3. Cuba CAC, Marsden PD, Barreto AC, Jones TC, Richards F. The use of different concentrations of leishmanial antigen in skin testing to evaluate delayed hypersensitivity in American cutaneous leishmaniasis. Revista da Sociedade Brasileira de Medicina Tropical 18: 231-236, 1985.

4. Lima LC, Ruralização da Lutzomyia intermedia, um provável caso de pré-adaptação. Revista de Saúde Pública, Sāo Paulo 20: 102-104, 1986.

5. Marsden PD, Nonata RR. Mucocutaneous leishmaniasis - a review of clinical aspects. Revista da Sociedade Brasileira de Medicina Tropical 9: 309-326, 1975.

6. Mayrink W, Melo MN, Costa CA, Magalhães PA, Dias M, Coelho MV, Araújo FG, Williams P, Figueiredo YP, Batista SM. Intradermorreação de Montenegro na leishmaniose tegumentar americana após terapêutica antimonial. Revista do Instituto de Medicina Tropical de São Paulo 18: 182-185, 1976.

7. Montenegro J. Cutaneous reaction in leishmaniasis. Archives of Dermatology and Syphilis 13: 187-194, 1926.

8. Nimer E. Clima. In: Brasil. Fundação Instituto Brasileiro de Geografia e Estatística. Rio de Janeiro. Geografia do Brasil - Região Sul 5: 35-79, 1977.

9. Pessôa SB, Martins AV. Pessôa Parasitologia Médica. Guanabara-Koogan. Rio de Janeiro 10 ed. p. 86, 1977.

10. Tavares Neto J, Costa JML, Marsden PD, Barreto AC, Cuba CC. Composiçāo racial e a avaliação da reação intradérmica de Montenegro em portadores da leishmaniose cutâneo-mucosa. Revista da Sociedade Brasileira de Medicina Tropical 19: 75-78, 1986. 